\title{
Loss of heterozygosity, aberrant methylation, BRAF mutation and KRAS mutation in colorectal signet ring cell carcinoma
}

\author{
Sanjay Kakar ${ }^{1,2}$, Guoren Deng ${ }^{2}$, Thomas C Smyrk ${ }^{3}$, Lisa Cun², Vaibhav Sahai ${ }^{4}$ \\ and Young $\mathrm{S} \mathrm{Kim}{ }^{2}$ \\ ${ }^{1}$ Department of Pathology, Veteran Affairs Medical Center and University of California, San Francisco, \\ San Francisco, CA, USA; ${ }^{2}$ Gastrointestinal Research Laboratory, Veteran Affairs Medical Center, \\ San Francisco, CA, USA; ${ }^{3}$ Department of Pathology, Mayo Clinic, Rochester, MN, USA and \\ ${ }^{4}$ Department of Hematology-Oncology, Northwestern University, Chicago, IL, USA
}

\begin{abstract}
The relationship of molecular abnormalities with clinicopathologic features and survival in colorectal signet ring cell carcinoma, and its comparison with mucinous and conventional adenocarcinomas, has not been well studied. High-level microsatellite instability, loss of heterozygosity (LOH) at four loci, CpG island methylation phenotype based on seven loci, BRAF V600E mutation and KRAS mutation in signet ring cell carcinoma were compared with mucinous and conventional adenocarcinomas. The relationship of these molecular features in signet ring cell carcinoma with clinicopathologic features and survival was examined. LOH was observed in $93 \%$ of signet ring cell carcinomas compared with 62 and $70 \%$ of mucinous and conventional adenocarcinomas. Also, $80 \%$ of signet ring cell carcinomas with high-level microsatellite instability showed LOH compared with $14 \%$ each of mucinous and conventional adenocarcinomas. High-level microsatellite instability, CpG island methylation phenotype-positive status and BRAF V600E mutation were more often seen in signet ring cell carcinoma and mucinous adenocarcinoma compared with conventional adenocarcinoma. BRAF V600E mutation was significantly associated with CpG island methylation phenotype-positive status. Stage and BRAF V600E mutation in microsatellite-stable cases were the only variables with an affect on survival. In conclusion, chromosomal instability manifested by LOH is nearly a universal finding in signet ring cell carcinoma, including cases with highlevel microsatellite instability. This may explain the aggressive behavior of signet ring cell carcinoma irrespective of high-level microsatellite-instability status. BRAF V600E mutation and CpG island methylation phenotypepositive status are similar in signet ring cell carcinoma and mucinous adenocarcinoma but more frequent when compared with conventional adenocarcinoma. In signet ring cell carcinoma, BRAF V600E mutation adversely affects survival in microsatellite-stable tumors, but not in high-level microsatellite-unstable tumors. The high frequency of methylation and BRAF V600E mutation suggests that many signet ring cell carcinomas may be related to the serrated pathway of carcinogenesis.

Modern Pathology (2012) 25, 1040-1047; doi:10.1038/modpathol.2012.44; published online 20 April 2012
\end{abstract}

Keywords: BRAF; KRAS; LOH; methylation; signet ring

Signet ring cell carcinoma is a rare subtype of colorectal cancer associated with a poor prognosis. ${ }^{1-10}$ By definition, $>50 \%$ of tumor cells have signet ring cell morphology. ${ }^{11}$ Signet ring histology is

Correspondence: Dr S Kakar, MD, Department of Anatomic Pathology, UCSF, VA Medical Center, 4150 Clement Street, San Francisco, CA 94121, USA.

E-mail: sanjay.kakar@ucsf.edu

Received 11 October 2011; revised 16 December 2011; accepted 21 December 2011; published online 20 April 2012 considered an independent adverse prognostic factor by the American Joint Committee on Cancer and the College of American Pathologists. ${ }^{12,13}$ Colon cancer is thought to arise via one of several relatively distinct pathways. ${ }^{14}$ It is not clear how the signet ring cell phenotype fits into one or more putative pathways.

High-level microsatellite instability has been observed in approximately one-third of signet ring cell carcinomas. ${ }^{15}$ Although high-level microsatellite instability is considered a favorable prognostic factor in colorectal cancer, it does not favorably 
influence survival in signet ring cell carcinoma. ${ }^{15}$ The reason for this discrepancy is not clear. It is well established that high level of chromosomal instability is associated with aggressive behavior in colorectal cancer. ${ }^{16-18}$ Chromosomal instability in colorectal cancer manifests as allelic gains or losses at multiple sites in the genome, leading to inactivation of tumor-suppressor genes. The most commonly affected loci are $5 \mathrm{q}(A P C), 17 \mathrm{p}$ (TP53), 18q (DCC, $S M A D 2$ and $S M A D 4$ ) and $8 \mathrm{q}$ (no candidate gene identified). ${ }^{18,19}$ Other abnormalities include chromosomal losses at $1 p, 2 p, 3 p, 6 q, 14 q$ and $15 q$, and gains of $20 q, 13 q, 7 q$ and $8 q .{ }^{17-19}$

The role of transcriptional silencing of tumorsuppressor genes by aberrant methylation of promoter region has been widely studied in colorectal cancer. $^{20-25}$ The term CpG island methylator phenotype has been used for classifying colorectal cancers based on promoter methylation of multiple genes, although there is no universally accepted definition of $\mathrm{CpG}$ island methylation phenotype-positive tumors. Some, but not all, studies have shown that CpG island methylation phenotype-positive phenotype is associated with aggressive behavior. ${ }^{26-30}$

$B R A F$ is a downstream gene in the KRAS pathway. $B R A F$ V600E mutation occurs in $34-80 \%$ of cancers with high level of microsatellite instability and $5-15 \%$ of microsatellite-stable cancers. ${ }^{31-34} B R A F$ V600E mutation has been associated with poor survival in patients with microsatellite-stable, but not microsatellite-unstable, colorectal cancers. ${ }^{31-34}$ In fact, $B R A F$ V600E mutation does not adversely affect the favorable survival associated with tumors that show high level of microsatellite instability. ${ }^{31}$

Although genetic and epigenetic changes in colorectal cancer have been extensively studied, there are sparse data on the molecular features of signet ring cell carcinoma. ${ }^{15,35}$ The relationship of molecular changes and survival in signet ring cell carcinoma remains unclear. It is likely that signet ring morphology is a marker for genetic abnormalities that confer the aggressive behavior associated with signet ring cell carcinoma irrespective of microsatellite-instability status. This study examines microsatelliteinstability status, methylation, $B R A F$ mutation, KRAS mutation and chromosomal instability in colorectal signet ring cell carcinoma, and the association of these abnormalities with survival. The characteristics of signet ring cell carcinoma are also compared with mucinous and conventional adenocarcinomas.

\section{Materials and methods}

\section{Colorectal Cancer Cases}

The study group comprised 33 cases of signet ring carcinoma from University of California, San Francisco (San Francisco, CA, USA), Veteran Affairs Medical Center (San Francisco, CA, USA) and Mayo Clinic (Rochester, MN, USA). Signet ring cells accounted for $>50 \%$ of the tumor cells in all cases in accordance with the World Health Organization definition. Clinical parameters, including age, gender, date of surgery, tumor size, site and stage, were obtained from the pathology reports. Tumors in the cecum, ascending colon and transverse colon were classified as right sided and those in the descending colon, sigmoid and rectum were left sided. Cancers arising in the setting of underlying conditions like inflammatory bowel disease, familial adenomatous polyposis and hereditary nonpolyposis colorectal cancer were excluded. Information about distant metastases and 5-year survival was obtained from the hospital tumor registries. Depth of tumor invasion, lymph node status and clinical information were used to assign tumor stage using the system described in the American Joint Committee on Cancer Staging Manual. ${ }^{12}$ The study was approved by the respective institutional review boards.

\section{DNA Extraction}

DNA extracted from formalin-fixed, paraffin-embedded tissue was used for analysis. A desired area of the normal and tumor tissue was selected on formalin-fixed, paraffin-embedded sections stained with hematoxylin and eosin. The selected tissue was scraped off from $10 \mu \mathrm{m}$-thick sections under microscopic guidance. The normal tissue was located at least $1 \mathrm{~cm}$ from the tumor. The microdissected tissue was incubated overnight at $56{ }^{\circ} \mathrm{C}$ in $100 \mu$ l solution containing 0.5\% Tween 20 (Sigma, St Louis, MO, USA), $100 \mathrm{mM}$ of Tris-HCl (pH 7.6), $1 \mathrm{mM}$ of EDTA and $20 \mu \mathrm{g}$ of proteinase K (Sigma). Proteinase K was then inactivated by incubating at $95{ }^{\circ} \mathrm{C}$ for $10 \mathrm{~min}$ and the extracted DNA was stored at $-20^{\circ} \mathrm{C}$.

\section{Chromosomal-Instability Analysis}

Chromosomal instability was determined by loss of heterozygosity (LOH) analysis using paired normal and tumor DNA as previously described. The extracted DNA served as a template for PCR as described previously. ${ }^{26,27}$ Four loci commonly lost in colorectal cancer were employed for determination of LOH: $5 q 21$ (location of the APC gene), 8p12-22 (no known tumor-suppressor gene), 17p13 (location of $p 53$ gene) and 18q21 (location of DCC gene). The PCR at each locus was carried out using tetranucleotide primers at each locus. These included D5S1461, D5S1453, D5S1466, D5S1468 and D5S1478 for chromosome 5q21 region, D8S1130, D8S1106, D8S1463, D8S1125, D8S1121, D8S255 and D8S1098 for chromosome 8p12-22 region; D17S1298, D17S1537, D17S1541 and D17S1303 for chromosome 17p13 region; and D18S877, D18S536, D18S846, D18S851 and D18S858 for chromosome 18q21 region. After normalizing the ratio of two alleles from the normal mucosa, tumors with ratio $<0.5$ or $>2.0$ were considered as having LOH. Cases with $\mathrm{LOH}$ at any locus were scored as LOH-positive, 
and the rest as LOH-negative. Although $\mathrm{LOH}$ was evaluated at only four loci, this technique has been validated by correlating the results with array-based comparative genomic hybridization analysis in colorectal cancer. We were able to demonstrate a high correlation between chromosomal instability detected by array-based comparative genomic hybridization and by $\mathrm{LOH}$ at four loci selected for this study. ${ }^{36}$

\section{Microsatellite Instability, CpG Island Methylation Phenotype Status, BRAF Mutation and KRAS Mutations}

The microsatellite-instability status was determined by PCR at seven microsatellite markers: BAT25, BAT26, D5S1453, D8S1130, D11S1999, D17S1537 and D18S877. Tumors with instability at $\geq 3$ markers were classified as microsatellite unstable and the remaining as microsatellite stable. The methylation status was evaluated by examining seven loci: hMLH1, p16, HIC1, RASSF2, ID4, MINT1 and MINT31. Methylation was determined by methylation-specific PCR assay using sodium bisulfitetreated DNA. Tumors with methylation at $\geq 3$ loci were classified as $\mathrm{CpG}$ island methylator phenotype-positive and the remaining as $\mathrm{CpG}$ island methylator phenotype-negative. BRAF V600E mutation analysis was done by allele-specific PCR, whereas KRAS mutations at codons 12 and 13 were detected by PCR reaction followed by sequencing.

\section{Comparison with Mucinous and Nonmucinous Adenocarcinomas}

The molecular features and 5-year survival in signet ring cell carcinomas were compared with those of mucinous carcinomas $(n=26)$ and conventional adenocarcinomas $(n=57)$ as described in a previous study. ${ }^{37}$

\section{Statistical Analysis}

The relationship between variables was tested by $\chi^{2}$ and Fisher's exact tests. These tests were also used for comparison between signet ring cell carcinoma, mucinous carcinoma and conventional adenocarcinoma. For survival analysis, the starting point for survival time was the date of surgery. Survival curves were calculated using the Kaplan-Meier method with statistical comparison tested by the log-rank test. Survival curves were calculated using the Kaplan-Meier method with statistical significance between curves tested by the log-rank test. Univariate analysis was performed using Cox proportional hazards model; the hazard ratio and its 95\% confidence intervals were assessed for each factor. The $P$-values of $<0.05$ were considered statistically significant. The survival analysis was
Table 1 LOH, methylation and 5-year survival in MSI-H and MSS signet ring colorectal cancers

\begin{tabular}{|c|c|c|c|}
\hline & $M S I-H(\mathrm{n}=8)$ & $M S S(\mathrm{n}=25)$ & $\mathrm{P}$-value \\
\hline \multicolumn{4}{|l|}{ Age } \\
\hline$\leq 60$ years & $2(25)$ & $18(72)$ & \multirow[t]{2}{*}{0.02} \\
\hline$>60$ years & $6(75)$ & $7(28)$ & \\
\hline \multicolumn{4}{|l|}{ Gender } \\
\hline Female & $2(25)$ & $7(28)$ & \multirow[t]{2}{*}{0.34} \\
\hline Male & $6(75)$ & $18(72)$ & \\
\hline \multicolumn{4}{|l|}{ Site } \\
\hline Right & $6(75)$ & $10(40)$ & \multirow[t]{2}{*}{0.09} \\
\hline Left & $2(25)$ & $15(60)$ & \\
\hline \multicolumn{4}{|l|}{$L O H(\mathrm{n}=15)$} \\
\hline Present & $4(80)$ & $10(100)$ & \multirow[t]{2}{*}{0.33} \\
\hline Absent & $1(20)$ & 0 & \\
\hline \multicolumn{4}{|l|}{ Methylation } \\
\hline 0-2 loci & $2(25)$ & $15(60)$ & \multirow[t]{2}{*}{0.08} \\
\hline$\geq 3$ loci (CIMP+) & $6(75)$ & $10(40)$ & \\
\hline \multicolumn{4}{|l|}{ BRAF } \\
\hline Mutant & $3(43)$ & $6(30)$ & \multirow[t]{2}{*}{0.30} \\
\hline Wild & $4(57)$ & $14(70)$ & \\
\hline \multicolumn{4}{|l|}{ KRAS } \\
\hline Mutant & $2(29)$ & $14(61)$ & \multirow[t]{2}{*}{0.12} \\
\hline Wild & $5(71)$ & $9(39)$ & \\
\hline \multicolumn{4}{|l|}{ 5-Year survival } \\
\hline Alive & $4(50)$ & $7(28)$ & \multirow{2}{*}{0.17} \\
\hline Dead & $4(50)$ & $18(72)$ & \\
\hline
\end{tabular}

Figures in parenthesis reflect percentages.

completed using the SAS v9.2 (SAS Institute, Cary, NC, USA).

\section{Results}

\section{Signet Ring Cell Carcinoma: Clinicopathologic and Molecular Characteristics}

The mean age was 56.4 years (range 26-90 years); there were 24 men and 9 women. The tumors were nearly equally distributed in the colon (17 left sided and 16 right sided). At presentation, 7 patients had early-stage disease (I and II), whereas 19 cases had stage III disease and 7 cases had stage IV disease.

Of the 15 cases in which LOH status was determined, 14 (93\%) showed $\mathrm{LOH}$ involving at least one locus. Of these 14 cases, 4 showed highlevel microsatellite instability and 10 were microsatellite stable; the LOH-negative case had high-level microsatellite instability. Two or more loci were affected in 5 cases. The most common abnormality was loss of 18q (6 cases), followed by $17 \mathrm{p}$ loss ( 4 cases), $5 q$ loss (4 cases) and $8 p$ loss (3 cases).

High-level microsatellite instability was present in $8(24 \%)$ signet ring cell carcinoma cases (Table 1$)$. High-level microsatellite-instability status was significantly associated with advanced age and female gender; there was borderline association 
with right-sided location. There was no significant difference in LOH between tumors with high-level microsatellite instability and tumors that were microsatellite stable $(80 \%$ vs $100 \%, P=0.3)$. $B R A F$ V600E mutation was more common in tumors with high-level microsatellite instability than microsatellite-stable tumors ( $43 \%$ vs $30 \%)$, whereas KRAS mutation was more common in microsatellite-stable cases (61\% vs 29\%), but these differences did not reach statistical significance.

$\mathrm{CpG}$ island methylation phenotype-positive status ( $\geq 3$ markers methylated) was identified in 16 (48\%) cases. Age, gender, site, high-level microsatellite instability and KRAS mutation were not associated with $\mathrm{CpG}$ island methylation phenotype-positive status. Of the 27 cases in which BRAF V600E mutation analysis yielded informative results, the mutation was observed in 8/12 (67\%) CpG island methylation phenotype-positive tumors compared with 1/15 (7\%) in CpG island methylation phenotype-negative tumors $(P=0.002)$.

Informative results on BRAF V600E and KRAS mutations were obtained in 27 and 30 cases, respectively. BRAF V600E mutation was observed in $9(33 \%)$ cases. Age, gender, site and high-level microsatellite instability were not associated with $B R A F$ V600E mutation. CpG island methylation phenotype-positive status was observed in $89 \%$ tumors with $B R A F$ V600E mutation compared with $22 \%$ in tumors lacking the mutation $(P=0.002)$. KRAS mutation was present in 16 (53\%) cases, and did not correlate with any clinicopathologic or molecular feature.

\section{Survival in Signet Ring Cell Carcinoma}

The 5-year survival in signet ring cell carcinoma was $33 \%$. In univariate analysis, high stage had a borderline adverse effect on 5-year survival $(P=0.05$, Figure 1). When only microsatellite-stable cases were considered, $B R A F$ V600E mutation had a

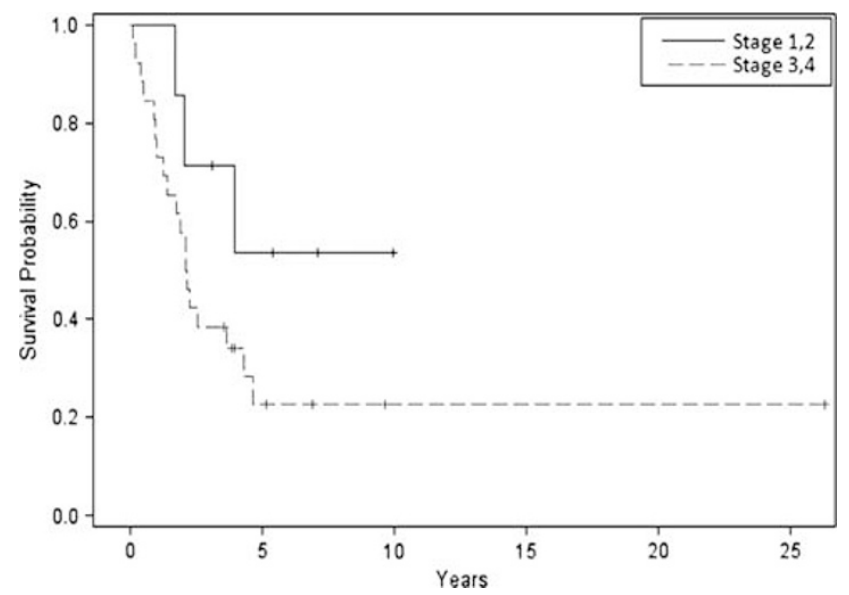

Figure 1 Stage of the tumor and 5-year survival in signet ring carcinoma. significant adverse affect on 5 -year survival ( $0 \%$ vs $43 \%, P=0.006$, Table 2 and Figure 2). None of the 9 cases with $B R A F$ V600E mutation showed 5-year survival (stage I/II: 2 cases, stage III: 3 cases, stage IV: 4 cases). In contrast to microsatellite-stable cases, $B R A F$ V600E mutation had no significant affect on survival in cases with high-level microsatellite instability. Other parameters like age, gender, site, microsatellite-instability status, CpG island methylation phenotype-positive status and KRAS mutation did not significantly influence 5-year survival. Multivariate analysis was not performed because of the small number of cases.

\section{Comparison of Signet Ring Cell Carcinoma with Mucinous Carcinoma and Conventional Adenocarcinoma}

Signet ring cell carcinoma patients were significantly younger and had advanced stage at presentation compared with mucinous carcinoma and conventional adenocarcinomas (Table 3). There was no difference in gender and site among the three histologic subtypes. LOH-positive status was observed in $93 \%$ of signet ring cell carcinomas compared with $62 \%$ in mucinous carcinomas $(P=0.02)$ and $70 \%$ in conventional adenocarcinomas $(P=0.04)$. Microsatellite instability, CpG island methylation phenotype-positive status and $B R A F$ V600E mutations were similar in signet ring cell carcinoma and mucinous carcinoma, but occurred more often compared with conventional adenocarcinoma (Table 2). KRAS mutations were similar in signet ring cell carcinoma and conventional adenocarcinoma, but were more frequent when compared with mucinous carcinoma.

The overall 5-year survival in signet ring cell carcinoma was $33 \%$ compared with $50 \%$ for mucinous carcinoma $(P=0.09)$ and $63 \%$ for conventional adenocarcinoma $(P=0.004)$. Among patients with advanced-stage disease (stage III and IV), the 5-year survival was $27 \%$ for signet ring cell carcinoma (Table 3) compared with $43 \%$ for

Table 2 Impact of factors on survival in colorectal signet ring carcinoma as estimated by the Cox model

\begin{tabular}{lccc}
\hline Variable & $\begin{array}{c}\text { Hazard } \\
\text { ratio }\end{array}$ & $\begin{array}{c}\text { 95\% Hazard ratio } \\
\text { confidence limits }\end{array}$ & P-value \\
\hline Age & 1.002 & $0.979-1.026$ & 0.84 \\
Gender & 1.030 & $0.419-2.533$ & 0.95 \\
Size & 0.888 & $0.732-1.076$ & 0.23 \\
Site & 1.138 & $0.492-2.636$ & 0.76 \\
MSI-H & 0.415 & $0.139-1.240$ & 0.12 \\
CIMP+ & 1.188 & $0.512-2.577$ & 0.69 \\
$\begin{array}{l}\text { KRAS mutation } \\
\text { BRAF V600E mutation } \\
\text { (all cases) }\end{array}$ & 1.172 & $0.609-2.258$ & 0.63 \\
$\begin{array}{l}\text { BRAF V600E (MSS } \\
\text { cases only) }\end{array}$ & 5.178 & $0.880-2.384$ & 0.15 \\
Stage & 2.433 & $1.589-16.879$ & 0.006 \\
\hline
\end{tabular}




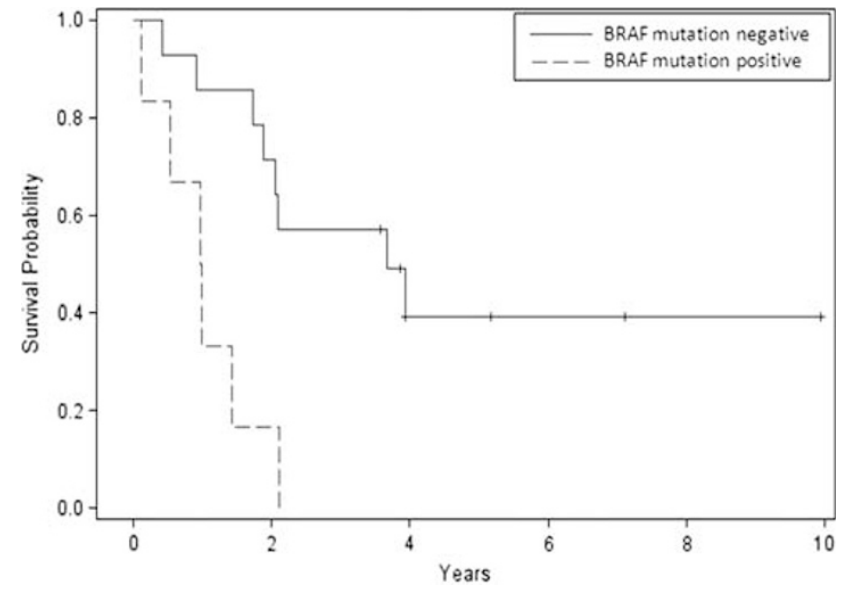

Figure 2 BRAF V600E mutation and 5-year survival in microsatellite-stable cases of signet ring carcinoma.

mucinous carcinoma $(P=0.14)$ and $57 \%$ for conventional adenocarcinoma $(P=0.03)$. When LOHpositive cases were considered in the three histologic subtypes, there was no significant difference in 5 -year survival in signet ring cell carcinoma (21\%), mucinous carcinoma $(33 \%)$ and conventional adenocarcinoma $(42 \% ; P=0.3)$.

\section{Discussion}

Signet ring cell carcinoma is a rare histologic subtype of colorectal cancer with a very poor prognosis. The reported 5-year survival in the literature is $9-37 \%,{ }^{1-10}$ which is comparable to the $33 \%$ survival in this study. The literature contains limited data on the molecular features of signet ring cell carcinoma. Some molecular features (high-level microsatellite instability, BRAF mutation and KRAS mutation) were examined by Ogino et $a l^{35}$ but the authors acknowledged that their series of eight cases was small. In this study, we analyzed the molecular features of 33 resected signet ring cell carcinomas and explored their correlation with outcome.

High-level microsatellite instability has been reported in $25-31 \%$ of signet ring cell carcinomas, ${ }^{15,35}$ which is similar to the $24 \%$ figure observed in this series. High-level microsatellite instability is a marker of favorable outcome in sporadic colorectal cancer, but does not favorably influence survival in signet ring cell carcinoma. ${ }^{14}$ In a large study of 70 signet ring cell carcinomas, the 5-year survival in cancers with and without high-level microsatellite instability was $41 \%$ and $34 \%$ respectively; this marginal difference was not statistically significant. ${ }^{15}$ The reason for aggressive behavior of signet ring cell carcinoma including tumors with high-level microsatellite instability is not clear. High-level microsatellite-unstable tumors tend to be diploid ${ }^{38}$ and chromosomal instability is a relatively infrequent phenomenon; $\mathrm{LOH}$ is observed in $16-21 \%$ of
Table 3 Comparison of clinicopathologic and molecular features of signet ring cell carcinoma with mucinous and conventional adenocarcinoma

\begin{tabular}{|c|c|c|c|c|}
\hline & $\begin{array}{c}S R C \\
(\mathrm{n}=33)\end{array}$ & $\begin{array}{c}M C \\
(\mathrm{n}=26)\end{array}$ & $\begin{array}{c}A C \\
(\mathrm{n}=57)\end{array}$ & $\mathrm{P}$-value \\
\hline \multicolumn{5}{|l|}{ Age } \\
\hline$\leq 60$ years & $20(61)$ & $6(23)$ & $17(30)$ & $0.004^{\mathrm{a}}$ \\
\hline$>60$ years & $13(39)$ & $20(77)$ & $40(70)$ & $0.004^{\mathrm{b}}$ \\
\hline \multicolumn{5}{|l|}{ Gender } \\
\hline Male & $24(72)$ & $17(65)$ & $36(63)$ & $0.19^{\mathrm{a}}$ \\
\hline Female & $9(28)$ & $9(35)$ & $21(37)$ & $0.25^{\mathrm{b}}$ \\
\hline \multicolumn{5}{|l|}{ Location } \\
\hline Right & $16(48)$ & $11(42)$ & $24(42)$ & $0.42^{\mathrm{a}}$ \\
\hline Left & $17(52)$ & $15(58)$ & $33(58)$ & $0.15^{\mathrm{b}}$ \\
\hline \multicolumn{5}{|l|}{ Stage } \\
\hline Low (I, II) & $7(21)$ & $10(38)$ & $38(66)$ & $0.08^{\mathrm{a}}$ \\
\hline High (III, IV) & $26(79)$ & $16(62)$ & $19(34)$ & $<0.001^{\mathrm{b}}$ \\
\hline \multicolumn{5}{|c|}{ Microsatellite status } \\
\hline MSI-H & $8(24)$ & $7(27)$ & $7(12)$ & $0.52^{\mathrm{a}}$ \\
\hline MSS & $25(76)$ & $19(73)$ & $50(88)$ & $0.12^{\mathrm{b}}$ \\
\hline \multicolumn{5}{|l|}{ LOH status } \\
\hline Positive & $14(93)$ & $16(62)$ & $40(70)$ & $0.02^{\mathrm{a}}$ \\
\hline Negative & $1(7)$ & $10(38)$ & $17(30)$ & $0.04^{\mathrm{b}}$ \\
\hline \multicolumn{5}{|c|}{$L O H$ in $M S I-H$ cases } \\
\hline Positive & $4(80)$ & $1(14)$ & $1(14)$ & $0.04^{\mathrm{a}}$ \\
\hline Negative & $1(20)$ & $6(84)$ & $6(84)$ & $0.04^{\mathrm{b}}$ \\
\hline \multicolumn{5}{|l|}{ CIMP status } \\
\hline Positive & $16(48)$ & $10(38)$ & $10(18)$ & $0.31^{\mathrm{a}}$ \\
\hline Negative & $17(52)$ & $16(62)$ & $47(82)$ & $0.002^{\mathrm{b}}$ \\
\hline \multicolumn{5}{|l|}{ BRAF mutation ${ }^{\mathrm{c}}$} \\
\hline Present & $9(33)$ & $12(46)$ & $9(16)$ & $0.14^{\mathrm{a}}$ \\
\hline Absent & $24(67)$ & $14(54)$ & $48(84)$ & 0.04 \\
\hline \multicolumn{5}{|l|}{ KRAS mutation ${ }^{\mathrm{c}}$} \\
\hline Present & $16(52)$ & $7(27)$ & $23(40)$ & $0.04^{\mathrm{a}}$ \\
\hline Absent & $14(48)$ & $19(73)$ & $34(60)$ & $0.18^{\mathrm{b}}$ \\
\hline \multirow[t]{2}{*}{ 5-Year survival } & $33 \%$ & $50 \%$ & $63 \%$ & $0.09^{\mathrm{a}}$ \\
\hline & $27 \%$ & $43 \%$ & $57^{\circ}$ & $0.004^{\mathrm{b}}$ \\
\hline \multirow{3}{*}{$\begin{array}{l}\text { 5-Year survival, } \\
\text { stage III, IV } \\
\text { 5-Year survival, } \\
\text { LOH+ cases }\end{array}$} & $27 \%$ & $43 \%$ & $5 \% \%$ & $\begin{array}{l}0.14^{\mathrm{a}} \\
0.03^{\mathrm{b}}\end{array}$ \\
\hline & $21 \%$ & $33 \%$ & $42 \%$ & $0.33^{\mathrm{a}}$ \\
\hline & & & & $0.30^{\mathrm{b}}$ \\
\hline
\end{tabular}

${ }^{\mathrm{a}}$ Signet ring carcinoma (SRC) vs mucinous carcinoma (MC).

${ }^{\mathrm{b}}$ SRC vs conventional adenocarcinoma (AC).

${ }^{\mathrm{C}}$ Data not available in some SRC cases.

cancers with high-level microsatellite instability, compared with $56-83 \%$ of microsatellite-stable tumors. ${ }^{38-40}$ Hence, it has been argued that chromosomal instability is not a major mechanism for carcinogenesis in high-level microsatellite-unstable tumors. ${ }^{41}$ Several studies have shown that chromosomal instability is an adverse prognostic factor in colorectal cancer. ${ }^{16-18,33}$ Gains and losses at chromosome arms increase with progression from adenoma to invasive carcinoma and from primary tumor to metastasis. ${ }^{19}$ Hence, the infrequent occurrence of chromosomal instability may be related to the better 
outcome observed in tumors with high-level microsatellite instability. However, signet ring cancers were either not included in these studies ${ }^{40}$ or the histologic details were not provided. ${ }^{39}$ Our study shows that chromosomal instability, as manifested by $\mathrm{LOH}$ at one or more of the four loci studied, is present in nearly all signet ring cell carcinomas, including those with high-level microsatellite instability. In one study, $\mathrm{LOH}$ at $18 \mathrm{q}$ was observed in $57 \%$ of signet ring cell carcinomas, but other loci were not examined. ${ }^{35}$ In comparison, we have previously reported $\mathrm{LOH}$ in $62 \%$ of mucinous and $70 \%$ of conventional colorectal adenocarcinomas. In contrast to $\mathrm{LOH}$ in $80 \%$ of signet ring cell carcinomas with high-level microsatellite instability, this phenomenon is observed in only $14 \%$ of cases with high-level microsatellite instability in mucinous and conventional adenocarcinomas. Hence, the frequent occurrence of LOH in signet ring cell carcinoma may negate the positive affect of high-level microsatellite instability on survival in signet ring cell carcinoma.

Colorectal cancers with high levels of DNA methylation have been designated as $\mathrm{CpG}$ island methylator phenotype-positive or CpG island methylation phenotype-high. ${ }^{20-23}$ It has been argued that CpG island methylation phenotype-positive tumors constitute a distinct subtype of colorectal cancer, and have been variously associated with different features such as $B R A F$ mutation, KRAS mutation, favorable prognosis and adverse outcome. ${ }^{24-30,42}$ These differences are likely related to different criteria used for defining $\mathrm{CpG}$ island methylation phenotype-positive status, as well as the number and type of markers used. The role of methylation in signet ring cell carcinoma has not been systematically explored. In one study, CpG island methylation phenotype-positive status was observed in $17 \%$ of cases with signet ring cells; however, the standard definition of signet ring cell carcinoma ( $>50 \%$ signet ring cells) was not used in this study. ${ }^{43} \mathrm{CpG}$ island methylation phenotype-positive status, as defined in this study, was observed in nearly half of the signet ring cell carcinomas, and was associated with BRAF V600E mutation, but did not correlate with any clinicopathologic feature or survival. This association of $\mathrm{CpG}$ island methylation phenotypepositive status with $B R A F$ V600E mutation is similar to that observed in other histologic subtypes of colorectal cancer. ${ }^{25,28,44}$

$B R A F$ V600E mutation occurs in the majority of sporadic colorectal cancers with high-level microsatellite instability and in 5-20\% of microsatellite status colorectal cancers. In this study, $B R A F$ V600E mutation was identified in one-third of signet ring cell carcinomas, which is comparable to the $22 \%$ figure reported by Ogino et $a .^{35} B R A F$ V600E mutation in our series has strong correlation with CpG island methylation phenotype-positive status, but not with any clinicopathologic or molecular features. Several studies have shown that $B R A F$ V600E mutation does not affect prognosis in colo- rectal cancers with high-level microsatellite instability, but adversely affects survival in microsatellitestable colorectal cancers. ${ }^{31-34}$ This phenomenon was also observed in signet ring cell carcinoma in this series with $43 \%$ 5-year survival in microsatellitestable cases lacking $B R A F$ V600E mutation compared with none among tumors with the mutation.

$B R A F$ V600E mutation and CpG island methylation phenotype-positive status are observed in a majority of serrated polyps and may be an early event in the serrated pathway of carcinogenesis. ${ }^{45,46}$ $B R A F$ V600E mutations and CpG island methylation phenotype-positive status were more common in signet ring cell carcinoma and mucinous adenocarcinoma compared with conventional adenocarcinoma. Similar observations regarding $B R A F$ V600E in signet ring cell carcinoma have been noted by Ogino et $a .^{35}$ Expression of the gastric mucin MUC5AC, a typical feature of serrated polyps, is also more common in mucinous and signet ring cell carcinomas, but is relatively uncommon in conventional adenocarcinoma. ${ }^{47-49}$ These findings suggest that a subset of signet ring cell carcinoma may be related to the serrated pathway of carcinogenesis.

$K R A S$ mutations have been have been reported in $27-43 \%$ of colorectal cancer. ${ }^{50}$ KRAS mutations in codons 12 and 13 were observed in half of signet ring cell carcinomas in this study, which is similar to the rate in conventional adenocarcinomas, but significantly more common than in mucinous carcinomas. The study by Ogino et $a l^{35}$ did not identify KRAS mutation in any of the 8 signet ring cell carcinoma cases, but this was seen in $33 \%$ of cases that had $<49 \%$ signet ring cells. Although the reason for this difference is not entirely clear, it is likely to be related to the small number of cases in their series. Although KRAS mutation has been extensively studied in colon cancer, its association with clinicopathologic features, survival or molecular features such as CpG island methylator phenotype status have yielded conflicting results. ${ }^{42,50}$ In our series, KRAS mutation status was not associated with any clinicopathologic features or survival in signet ring cell carcinoma. KRAS and/or $B R A F$ V600E mutations were seen in $79 \%$ of signet ring cell carcinomas. Recent experience has demonstrated the benefit of epidermal growth factor receptor inhibitors in metastatic colorectal cancers, but these agents are not useful in tumors with KRAS or $B R A F$ mutations. ${ }^{51,52}$ In view of the presence of these mutations in a vast majority of signet ring cell carcinoma, it is unlikely that anti-epidermal growth factor receptor therapy will be beneficial.

In summary, $\mathrm{LOH}$ at one or more loci was identified in nearly all cases of signet ring cell carcinomas, including tumors with high-level microsatellite instability. It is likely that chromosomal instability confers aggressive behavior to signet ring cell carcinoma and overrides any favorable affect of high-level microsatellite instability. Aberrant methylation and $B R A F$ V600E mutations are common in 
signet ring cell carcinomas, a phenomenon similar to mucinous adenocarcinomas. BRAF V600E mutation is associated with poor outcome in microsatellitestable signet ring cell carcinoma cases. CpG island methylation phenotype-positive phenotype and $K R A S$ mutation have been identified as markers of poor outcome in conventional microsatellite-stable colorectal adenocarcinomas, but these associations were not observed in signet ring cell carcinomas.

\section{Acknowledgement}

This work was supported by VA Merit Review grant, which was administered by the Northern California Institute for Research and Education, and with resources of the Veterans Affairs Medical Center, San Francisco, California.

\section{Disclosure/conflict of interest}

The authors declare no conflict of interest.

\section{References}

1 Secco GB, Fardelli R, Campora E, et al. Primary mucinous adenocarcinomas and signet-ring cell carcinomas of colon and rectum. Oncology 1994;51:30-34.

2 Tung SY, Wu CS, Chen PC. Primary signet ring cell carcinoma of colorectum: an age- and sex-matched controlled study. Am J Gastroenterol 1996;91: 2195-2199.

3 Nissan A, Guillem JG, Paty PB, et al. Signet-ring cell carcinoma of the colon and rectum: a matched control study. Dis Colon Rectum 1999;42:1176-1180.

4 Kawabata Y, Tomita N, Monden T, et al. Molecular characteristics of poorly differentiated adenocarcinoma and signet-ring-cell carcinoma of colorectum. Int J Cancer 1999;84:33-38.

5 Psathakis D, Schiedeck TH, Krug F, et al. Ordinary colorectal adenocarcinoma vs. primary colorectal signet-ring cell carcinoma: study matched for age, gender, grade, and stage. Dis Colon Rectum 1999;42: 1618-1625.

6 O’Connell JB, Maggard MA, Ko CY. Colon cancer survival rates with the new American Joint Committee on Cancer sixth edition staging. J Natl Cancer Inst 2004;96:1420-1425.

7 Kang H, O’Connell JB, Maggard MA, et al. A 10-year outcomes evaluation of mucinous and signet-ring cell carcinoma of the colon and rectum. Dis Colon Rectum 2005;48:1161-1168.

8 Makino T, Tsujinaka T, Mishima $\mathrm{H}$, et al. Primary signet-ring cell carcinoma of the colon and rectum: report of eight cases and review of 154 Japanese cases. Hepatogastroenterology 2006;53:845-849.

9 Song W, Wu SJ, He YL, et al. Clinicopathologic features and survival of patients with colorectal mucinous, signet-ring cell or non-mucinous adenocarcinoma: experience at an institution in southern China. Chin Med J (Engl) 2009;122:1486-1491.

10 Min BS, Kim NK, Ko YT, et al. Clinicopathological features of signet-ring cell carcinoma of the colon and rectum: a case-matched study. Hepatogastroenterology 2009;56:984-988.

11 Hamilton SR, Vogelstein B, Kudo S, et al. Carcinoma of the colon and rectum. In: Hamilton SR, Aaltonen LA (eds). Pathology and Genetics of Tumors of the Digestive System. IARC Press: Lyon, 2000, pp 105-119.

12 Edge SB, Byrd DB, Compton CC, et al. (eds). Colon and rectum. American Joint Committee on Cancer, Cancer Staging Manual 7th edn. Springer: New York, NY, 2011, pp 143-158.

13 Washington MK, Berlin J, Branton P, et al. Protocol for the examination of specimens from patients with primary carcinoma of the colon and rectum. Arch Pathol Lab Med 2009;133:1539-1551.

14 Whitehall V, Leggett B. Role of the serrated pathway in colorectal cancer pathogenesis. Gastroenterology 2010;138:2088-2100.

15 Kakar S, Smyrk TC. Signet ring cell carcinoma of the colorectum: correlations between microsatellite instability, clinicopathologic features and survival. Mod Pathol 2005;18:244-249.

16 Jernvall P, Makinen MJ, Karttunen TJ, et al. Morphological and genetic abnormalities in prediction of recurrence in radically operated colorectal cancer. Anticancer Res 1999;19:1357-1362.

17 De Angelis PM, Stokke T, Beigi M, et al. Prognostic significance of recurrent chromosomal aberrations detected by comparative genomic hybridization in sporadic colorectal cancer. Int J Colorectal Dis 2001;16: 38-45.

18 Choi SW, Lee KJ, Bae YA, et al. Genetic classification of colorectal cancer based on chromosomal loss and microsatellite instability predicts survival. Clin Cancer Res 2002;8:2311-2322.

19 Diep CB, Parada LA, Teixeira MR, et al. Genetic profiling of colorectal cancer liver metastases by combined comparative genomic hybridization and G banding analysis. Genes Chromosomes Cancer 2003; 36:189-197.

20 Toyota M, Issa JP. CpG island methylator phenotypes in aging and cancer. Semin Cancer Biol 1999;9:349-357.

21 Toyota M, Ohe-Toyota M, Ahuja N, et al. Distinct genetic profiles in colorectal tumors with or without the $\mathrm{CpG}$ island methylator phenotype. Proc Natl Acad Sci USA 2000;97:710-715.

22 van Rijnsoever M, Grieu F, Elsaleh H, et al. Characterisation of colorectal cancers showing hypermethylation at multiple CpG islands. Gut 2002;51:797-802.

23 Hawkins N, Norrie M, Cheong K, et al. CpG island methylation in sporadic colorectal cancers and its relationship to microsatellite instability. Gastroenterology 2002;122:1376-1387.

24 Ogino S, Cantor M, Kawasaki T, et al. CpG island methylator phenotype (CIMP) of colorectal cancer is best characterised by quantitative DNA methylation analysis and prospective cohort studies. Gut 2006;55:1000-1006.

25 Samowitz WS, Albertsen H, Herrick J, et al. Evaluation of a large, population-based sample supports a CpG island methylator phenotype in colon cancer. Gastroenterology 2005;129:837-845.

26 Lee S, Cho NY, Choi M, et al. Clinicopathological features of $\mathrm{CpG}$ island methylator phenotype-positive colorectal cancer and its adverse prognosis in relation to KRAS/BRAF mutation. Pathol Int 2008;58:104-113.

27 Lee S, Cho NY, Yoo EJ, et al. CpG island methylator phenotype in colorectal cancers: comparison of the 
new and classic CpG island methylator phenotype marker panels. Arch Pathol Lab Med 2008;132: 1657-1665.

28 Ogino S, Nosho K, Kirkner GJ, et al. CpG island methylator phenotype, microsatellite instability, BRAF mutation and clinical outcome in colon cancer. Gut 2009;58:90-96.

29 Dahlin AM, Palmqvist R, Henriksson ML, et al. The role of the $\mathrm{CpG}$ island methylator phenotype in colorectal cancer prognosis depends on microsatellite instability screening status. Clin Cancer Res 2010;16: 1845-1855.

30 Ang PW, Loh M, Liem N, et al. Comprehensive profiling of DNA methylation in colorectal cancer reveals subgroups with distinct clinicopathological and molecular features. BMC Cancer 2010;10:227.

31 Samowitz WS, Sweeney C, Herrick J, et al. Poor survival associated with the BRAF V600E mutation in microsatellite-stable colon cancers. Cancer Res 2005;65:6063-6069.

$32 \mathrm{Li}$ WQ, Kawakami K, Ruszkiewicz A, et al. BRAF mutations are associated with distinctive clinical, pathological and molecular features of colorectal cancer independently of microsatellite instability status. Mol Cancer 2006;5:2.

33 Kakar S, Deng G, Sahai V, et al. Clinicopathologic characteristics, CpG island methylator phenotype, and BRAF mutations in microsatellite-stable colorectal cancers without chromosomal instability. Arch Pathol Lab Med 2008;132:958-964.

34 Yokota T, Ura T, Shibata N, et al. BRAF mutation is a powerful prognostic factor in advanced and recurrent colorectal cancer. Br J Cancer 2011;104:856-862.

35 Ogino S, Brahmandam M, Cantor M, et al. Distinct molecular features of colorectal carcinoma with signet ring cell component and colorectal carcinoma with mucinous component. Mod Pathol 2006;19: 59-68.

36 Deng G, Nguyen A, Tanaka H, et al. Regional hypermethylation and global hypomethylation are associated with altered chromatin conformation and histone acetylation in colorectal cancer. Int J Cancer 2006;118:2999-3005.

37 Tanaka H, Deng G, Matsuzaki K, et al. BRAF mutation, CpG island methylator phenotype and microsatellite instability occur more frequently and concordantly in mucinous than non-mucinous colorectal cancer. Int J Cancer 2006;118:2765-2771.

38 Sinicrope FA, Rego RL, Halling KC, et al. Prognostic impact of microsatellite instability and DNA ploidy in human colon carcinoma patients. Gastroenterology 2006;131:729-737.

39 Goel A, Arnold CN, Niedzwiecki D, et al. Characterization of sporadic colon cancer by patterns of genomic instability. Cancer Res 2003;63:1608-1614.
40 Matsuzaki K, Deng G, Tanaka H, et al. The relationship between global methylation level, loss of heterozygosity, and microsatellite instability in sporadic colorectal cancer. Clin Cancer Res 2005;11:8564-8569.

41 Goel A, Nagasaka T, Arnold CN, et al. The CpG island methylator phenotype and chromosomal instability are inversely correlated in sporadic colorectal cancer. Gastroenterology 2007;132:127-138.

42 Nagasaka T, Koi M, Kloor M, et al. Mutations in both KRAS and BRAF may contribute to the methylator phenotype in colon cancer. Gastroenterology 2008; 134:1950-1960.

43 Nosho K, Irahara N, Shima K, et al. Comprehensive biostatistical analysis of $\mathrm{CpG}$ island methylator phenotype in colorectal cancer using a large populationbased sample. PLoS One 2008;3:e3698.

44 Chirieac LR, Shen L, Catalano PJ, et al. Phenotype of microsatellite-stable colorectal carcinomas with CpG island methylation. Am J Surg Pathol 2005;29: 429-436.

45 O’Brien MJ, Yang S, Mack C, et al. Comparison of microsatellite instability, $\mathrm{CpG}$ island methylation phenotype, BRAF and KRAS status in serrated polyps and traditional adenomas indicates separate pathways to distinct colorectal carcinoma end points. Am J Surg Pathol 2006;30:1491-1501.

46 Kim YH, Kakar S, Cun L, et al. Distinct CpG island methylation profiles and BRAF mutation status in serrated and adenomatous colorectal polyps. Int J Cancer 2008;123:2587-2593.

47 Biemer-Hüttmann AE, Walsh MD, McGuckin MA, et al. Immunohistochemical staining patterns of MUC1, MUC2, MUC4, and MUC5AC mucins in hyperplastic polyps, serrated adenomas, and traditional adenomas of the colorectum. J Histochem Cytochem 1999;47:1039-1048.

$48 \mathrm{Kim} \mathrm{DH}, \mathrm{Kim} \mathrm{JW}$, Cho JH, et al. Expression of mucin core proteins, trefoil factors, APC and p21 in subsets of colorectal polyps and cancers suggests a distinct pathway of pathogenesis of mucinous carcinoma of the colorectum. Int J Oncol 2005;27:957-964.

$49 \mathrm{Bu} \mathrm{XD,} \mathrm{Li} \mathrm{N,} \mathrm{Tian} \mathrm{XQ,} \mathrm{et} \mathrm{al.} \mathrm{Altered} \mathrm{expression} \mathrm{of}$ MUC2 and MUC5AC in progression of colorectal carcinoma. World J Gastroenterol 2010;16:4089-4094.

50 Mariani P, Lae M, Degeorges A, et al. Concordant analysis of KRAS status in primary colon carcinoma and matched metastasis. Anticancer Res 2010;30: 4229-4235.

51 Siddiqui AD, Piperdi B. KRAS mutation in colon cancer: a marker of resistance to EGFR-I therapy. Ann Surg Oncol 2010;17:1168-1176.

52 Laurent-Puig P, Cayre A, Manceau G, et al. Analysis of PTEN, BRAF, and EGFR status in determining benefit from cetuximab therapy in wild-type KRAS metastatic colon cancer. J Clin Oncol 2009;27:5924-5930. 